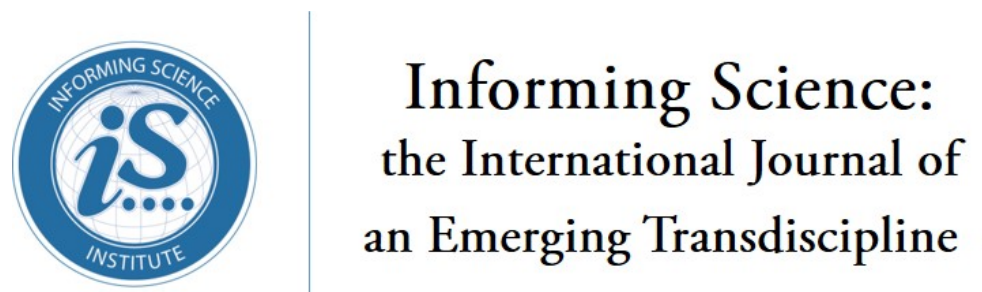

An Official Publication

of the Informing Science Institute

InformingScience.org

Inform.nu

Volume 22, 2019

\title{
SYNTHESIZING DESIGN AND INFORMING SCIENCE RATIONALES FOR DRIVING A DECENTRALIZED GENERATIVE KNOWLEDGE MANAGEMENT AgENDA
}

Ulrich Schmitt*

T. Grandon Gill

* Corresponding author
University of Stellenbosch, Business School, Bellville, South Africa

University of South Florida, Tampa, Florida, USA schmitt@,knowcations.org

grandon@usf.edu

ABSTRAC
Aim/Purpose
Background
Methodology
Contribution

Findings

Future Research

Keywords
In a world of rapidly expanding complexity and exponentially increasing data availability, IT-based knowledge management tools will be needed to manage and curate available information. This paper looks at a particular tool architecture that has been previously proposed: The Personal Knowledge Management System (PKMS). The specific focus is on how the proposed architecture conforms to design science principles that relate to how it is likely to evolve.

We first introduce some recent informing science and design science research frameworks, then examine how the PKMS architecture would conform to these.

The approach taken is conceptual analysis.

The analysis provides a clearer understanding of how the proposed PKMS would serve the diverse-client ambiguous-target (DCAT) informing scenario and how it could be expected to evolve.

We demonstrate how the PKMS informing architecture can be characterized as a "social machine" that appears to conform to a number of principles that would facilitate its long-term evolution.

The example provided by the paper could serve as a model future research seeking to integrate design science and informing science in the study of IT artefacts.

knowledge management, personal knowledge management system, design science research, design evolution, informing system, digital platform ecosystem, fitnessutility-model, generativity

Accepting Editor Eli Cohen | Received: December 18, 2018 | Revised: January 22, 2019 |

Accepted: March 14, 2019.

Cite as: Schmitt, U., \& Gill, T. G. (2019). Synthesizing design and informing science rationales for driving a decentralized generative knowledge management agenda. Informing Science: the International Journal of an Emerging Transdiscipline, 22, 1-18. https://doi.org/10.28945/4264

(CC BY-NC 4.0) This article is licensed to you under a Creative Commons Attribution-NonCommercial 4.0 International License. When you copy and redistribute this paper in full or in part, you need to provide proper attribution to it to ensure that others can later locate this work (and to ensure that others do not accuse you of plagiarism). You may (and we encourage you to) adapt, remix, transform, and build upon the material for any non-commercial purposes. This license does not permit you to use this material for commercial purposes. 


\section{INTRODUCTION}

In a world of ever-growing complexity and volume of information, how can we assist individuals in their quest to access and utilize that information effectively? One approach that has been proposed in the past (e.g., Schmitt, 2016a, 2017a) is the design, development and deployment of a Personal Knowledge Management System (PKMS). In summary, the proposed PKMS can be characterized as a social machine platform that would offer its collective users facilities for entering, representing, inter-relating, generating and accessing knowledge objects (referred to as memes) that are stored in its repository and allow for their digitally sharing, embedding and reusing as components of more complex digital documents (knowledge assets) via structural references (relationships).

A considerable amount has already been written about how such a PKMS could be designed (e.g., Schmitt, 2016a). One aspect of design that has received less attention in prior research is that of the proposed platform's ability to evolve over time in a dynamic knowledge environment. The obvious challenge in doing so is the recognition that complex environments tend to evolve unpredictably. In consequence, a design that is quite effective in one context may actually inhibit advances as that context changes (Gill, 1995).

An approach to predicting the ability of an informing artefact to evolve that has recently been advanced is the fitness-utility model (Gill \& Hevner, 2013). This model identifies characteristics that promote adaptation in evolutionary systems and proposes how they might be employed in evaluating the likelihood that a particular design will both survive and adapt. In the current paper, we focus our attention on understanding how the characteristics that promote long term survival proposed in the fitness-utility model might be present naturally or incorporated into the PKMS artefact and design process.

We begin by reviewing briefly two core concepts: the nature of informing systems and the fitnessutility model. We then present the basic PKMS architecture that has been proposed and consider the likely capacity of its key elements to evolve, enable, and empower according to the needs of the fitness-utility and other models. We then specifically look at where the PKMS fits within and contributes to the informing system framework and to design science research. Finally, we summarize our findings in a concluding section.

\section{INFORMING SYSTEMS AND FITNESS-UTILITY MODEL (FUT)}

The key building blocks of the present paper are the concept of an informing system, the fitnessutility model proposed in design science research, and the current knowledge management challenges the PKMS aims to address. Each of these is now reviewed briefly in turn.

\section{INFORMING SCIENCE AND INFORMING SYSTEMS}

The objective of Informing Science (IS) is to "provide their clientele with information in a form, format, and schedule that maximizes its effectiveness" (Cohen, 2009, p.6). The key building block of informing science is the Informing System, the collection of individuals and artefacts through which informing is accomplished. While such systems may involve ICT, it is not required that they do so (Gill, 2016).

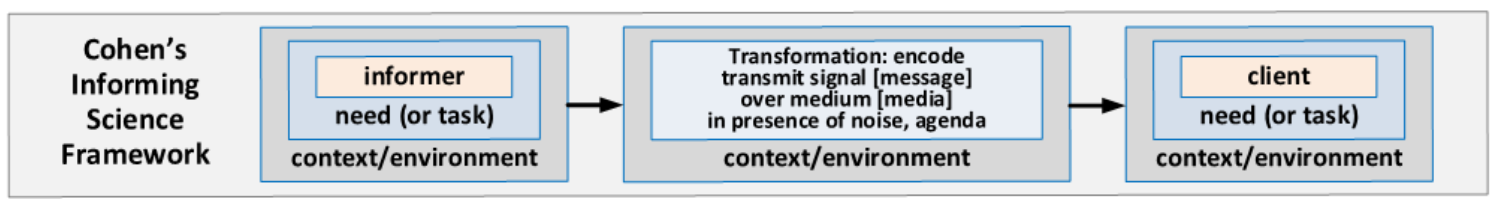

Figure 1. The basic informing system (adapted from Cohen, 2009)

The basic informing system is constructed using Shannon and Weaver's (1949) basic model of communications. It consists of an informer, a channel and a client, as illustrated in Figure 1. While real-world 
informing systems are necessarily more complex (e.g., multiple informers, multiple clients, multiple channels, bidirectional and broadcast channels, multiple informing layers, Gill, 2016), these three elements nevertheless play a role in each informing interaction.

From an informing perspective, a particularly challenging situation arises when an informing system must meet the needs of multiple clients, many of whom may have quite different objectives in being informed. One approach to visualizing this challenge, particularly likely in dynamic environments, is to picture informing activities as transitions between peaks in a rugged fitness landscape (Gill \& Mullarkey, 2017; Murphy, Murphy, Buettner, \& Gill, 2015). Combining the states of (single and multiple) starting and possible ending peaks among (single or diverse) clients allows for the clustering of four distinct quadrants (Figure 2) with distinct intervention scenarios.

- Bottom-Left: Need to determine a path that minimizes the duration and loss of fitness associated with the transition utilizing lectures, videos, or manuals by the informing agent.

- Bottom-Right: Different paths to the target may need to be established to accommodate the needs of different clients, self-paced learning with face-to-face tutorials and/or coaching.

- Top-Left: Moving clients 'set in their ways' to consider and/or pursue alternative peaks usually require assisting facilitators in order to shift paradigms and outside-the-box-thinking.

- Top-Right: This scenario is the most complex due to the inherent combinatorial explosion of potential informing paths to be considered. Generally speaking, the only way to address it (in the context of this article) is to create venues where clients take considerable responsibility for mapping out their own paths and are given the appropriate tools to do so.

It is precisely to accommodate the top-right diverse-clients-ambiguous-targets (DCAT) scenario that the PKM concept and system intends to address.

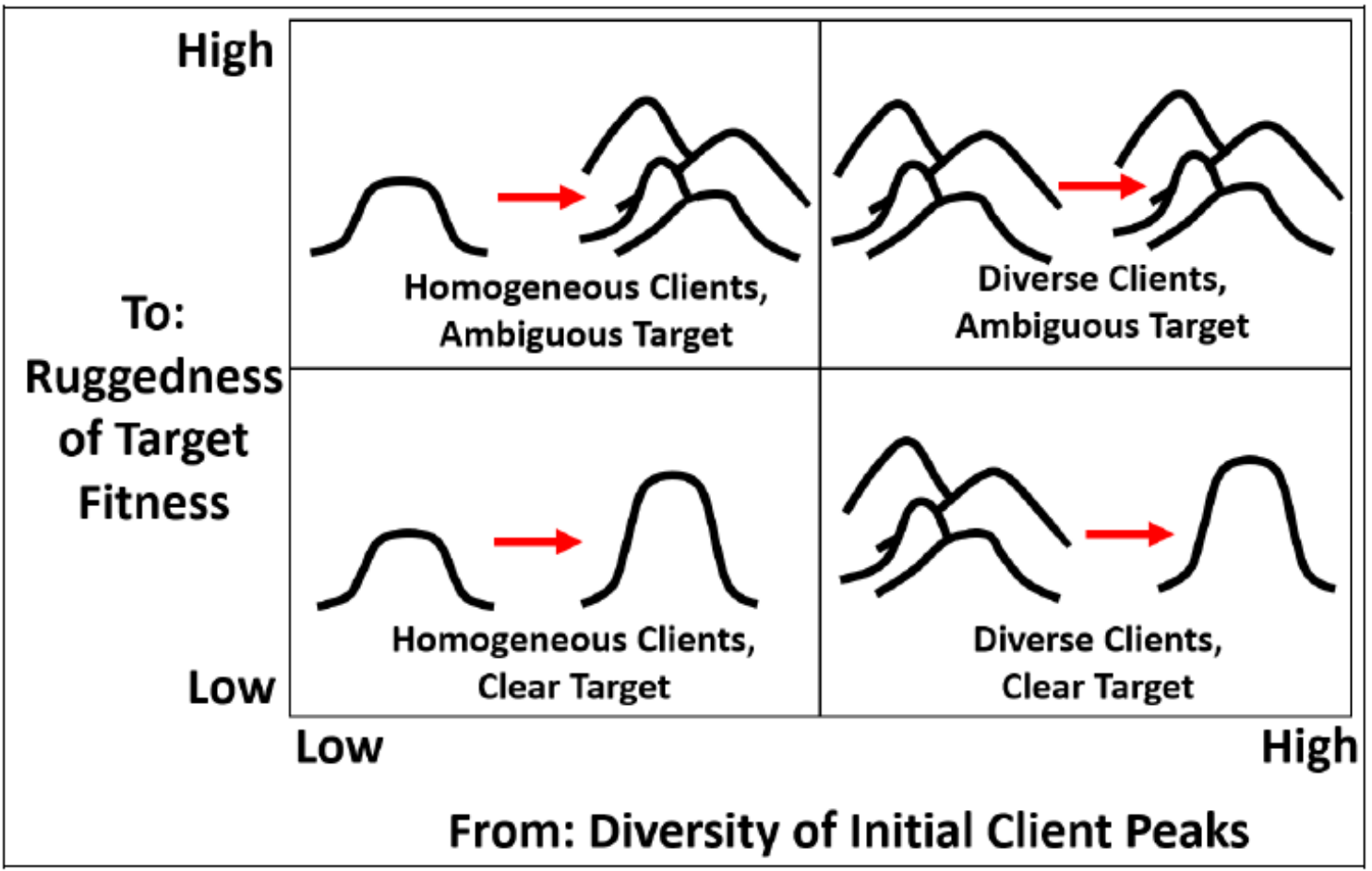

Figure 2. Possible scenarios in the informing task from the informer perspective (Murphy et al., 2015, p.69) 


\section{DESIGN SCIENCE FITNESS-UTILITY MODEL}

Design Science Research (DSR) is the study of the process through which effective artefacts are created. As applied within the area of information systems, such effectiveness entails satisfying "the requirements and constraints of the [informing] problem it was meant to solve" which can be considerably strengthened by integrating "the design science paradigm into the IS research community" (Hevner, March, Park, \& Ram, 2004, pp. 3, 13).

A potential problem associated with the original formulation of DSR was its emphasis on creating artefacts that were immediately useful. Indeed, it has been observed that some artefacts are so useful that they can serve to freeze subsequent innovation and adaptation (Gill \& Hevner, 2013). Effective undertakings also need to integrate dynamic perspectives to safeguard artefact utility "even in changing circumstances and contexts" (Drechsler, 2015, p. 33) by attending to "the evolutionary nature of design improvements [to assure] sustainable impacts" (Gill \& Hevner, 2013, p. 5:1). Accordingly, Gill and Hevner (2013, p. 5:14) argue for evaluating design artefacts based on the following evolutionary fitness characteristics, (concepts), and [disciplines], including:

- Too-Usefulness impacting highly on task performance but potentially lacking adaptability to changing circumstances (promoting individual and organizational achievement) - [economics and information management].

- Decomposability, Malleability, Openness, and Antifragility (promoting mutation, robustness, modification, and recombination) - [genetics].

- Novelty and Elegance (promoting diversity and longevity) - [evolutionary theory],

- Interestingness (promoting diffusion) - [innovation theory].

- Embeddedness in Design Systems to potentially evolve more rapidly (promoting quality, consistency, and motivation) - [technology acceptance theory].

In summary, therefore, they recommend that artefact design be rated on the presence or absence of features likely to promote or inhibit long term adaptation.

\section{THE GROWING CHALLENGE OF INFORMATION AND KNOWLEDGE}

As information accumulates at an ever-accelerating rate, our established practices to utilize that information effectively become unsustainable. We illustrate the problem with a model derived from Popper's interconnected Three Worlds' notion (1978). Figure 3 depicts the derived six digital ecosystems deemed relevant in the PKMS context according to that model (Schmitt, 2016a):

- the human intellectual record represented by the Physical Technology and Extelligence Ecosystem with its concrete objects and effects including information and communication technologies (World:1);

- the mental thought processes represented by the Knowledge Worker's Ecosystem with its more aggregated states of Institutions and Society Ecosystems and their subjective personal knowledge objects and social technologies (World:2); and

- the explicit thought content represented by the Ideosphere Ecosystem with its explicated abstract objective knowledge objects (World:3).

Each of the World: 1 and World:2 ecosystems is facing the most complex DCAT-scenario alluded to, for example: Fragmented Intellectual Knowledge Bases are poised to adapt to accelerating information abundance accompanied by growing entropy and (technological as well as disciplinary) compatibility issues; Knowledge Workers are confronted with widening opportunity divides and the need for life-longlearning to succeed in pursuing a diverse set of changing career paths; Institutions are encountering increasingly volatile, uncertain, complex and ambiguous challenges (VUCA environments) demanding adequate knowledge exploitation and exploration for survival; and Societies are contesting globally for the best ways to develop their knowledge economies for social peace and welfare. 


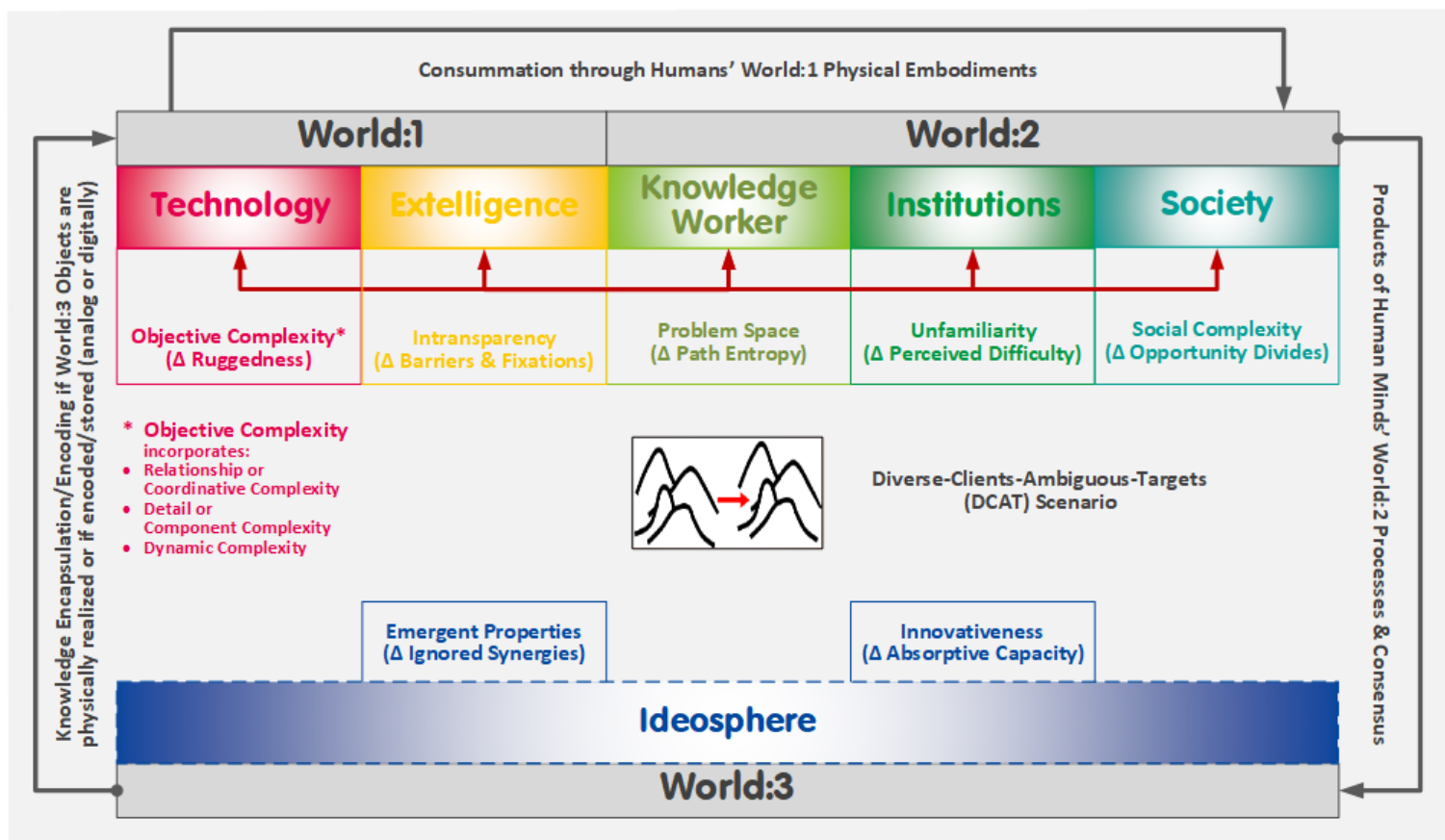

Figure 3. PKMS' digital ecosystems in their current unsustainable state

Each of these ecosystems are also dominated by particular complexities (objective complexity, intransparency, problem space, unfamiliarity, and social complexity, Gill \& Murphy, 2011). Moreover, all ecosystems are highly connected (Figure 3) embodying 'wicked problem spaces', defined as open-ended in the sense "that they are ill defined and characterized by incomplete, contradictory, and changing requirements and complex interdependencies and that the information needed to understand the problem depends upon one's idea for solving it" (Rylander, 2009).

Popper's World:3, on the other hand, constitutes currently a merely philosophical notion (termed Ideosphere Ecosystem in the PKMS concept). For Popper (1972), only formulated thoughts can be shared and criticized. As explicated objective content, these thoughts stand on their own (independent of their creators and able to be judged on their own merit) as abstract world:3 objects which - in their totality - represent the accumulated human extelligence which metaphorically bridges the world:2 minds with their world:1 concrete technologies and extelligence.

While this world:3 ideosphere can be understood as a holistic and negentropic representation of explicated knowledge, it is, unfortunately, "only a non-physical imaginary virtual construct and neither commonly accessible nor directly interrogatable" (Schmitt, 2018c, p. 16). Lacking instantiation at the current time, the ideosphere is unable to play a significant role in moderating the growing complexity we are facing and ineffective to address barriers, synergies, and capacities. It is here that we find the potential for a PKMS to play a significant role.

While diverse informing-science-related considerations have been addressed (Schmitt, 2015b, 2016a, 2017a, 2018b), an article also applies the SVIDT Methodology (Strengths, Vulnerability, Intervention Assessment related to Digital Threats) (Scholz, 2017)) by adopting a hindsight reverse-engineered logical perspective in order to present the line of reasoning from the proposed PKMS technologies back to the underlying motivations. It focused on the sustainability of PKM systems, processes, and outcomes in response to SVIDT's concerns with goals, environments, actors, affiliations, strengths, weaknesses, synergies, strategies, threat and intervention scenarios (Schmitt, 2018c). The following section adds a further angle by repurposing a design and evaluation framework used for evidencebased health care (Sedig, Naimi, \& Haggerty, 2017) to present the PKMS architecture and broad information flows. 


\section{PERSONAL KM System ARCHITECTURE AND ITS Ecosystems}

Zeroing in on this article's DCAT focus, the primary purpose of the PKMS is to provide a central service structure (Digital Platform Ecosystem or DPE) able to instantiate the ideosphere (Figure 4). DPEs are meant to accommodate social actors with highly diverse ambitions and skills. As users, they expect - in order to successfully navigate the DCAT scenario - to gainfully utilize the DPEs' resources and generative potential in their personal and local contexts (Eck \& Uebernickel, 2016, p.13).

DPEs embrace the notion of 'Generativity' which extends the dimensionality of mere ICT literacy with "the ability to generate new skills and knowledge that form the basis for innovation and creativity" as well as for understanding of IT concepts and artefacts including their complex, iterative processes (Pérez \& Murray, 2010, p. 132). Successfully establishing a system within these contexts requires not only to design a generative DPE and to attract a diverse user community "that can creatively engage with it" (Eck \& Uebernickel, 2016, p. 13), but also to position it within broader technological (as exemplified in Figure 4) and conceptual (as exemplified in Figure 5) ecosystems, always yielding the 'wicked' prospects (or risks) of (un)intentional (de)generative evolutions by effecting (un)anticipated (un)welcomed change.

A design and evaluation framework has recently been put forward for better anticipating, locating, and diagnosing the issues that arise when information technologies are used to achieve diverse information- and knowledge-intensive commitments in dynamic contexts. It is based on five distinct yet interdependent subsystems or spaces (information space, computation space, representation space, interaction space, and mental space). "Because each space contributes an essential presentation, representation, or process in the transformation of raw data and knowledge into usable and appropriately applied outcomes, the spaces do not exist or operate in isolation from one another; each contributes indispensably to the information flow required [and] must be designed to fulfill its specific role and to work in concert with the others, allowing information to flow freely among them for well-defined goals" (Sedig et al., 2017, p. 193). The five spaces also roughly correspond to the PKMSs' ecosystems and are, hence, used to structure their following condensed introductions.

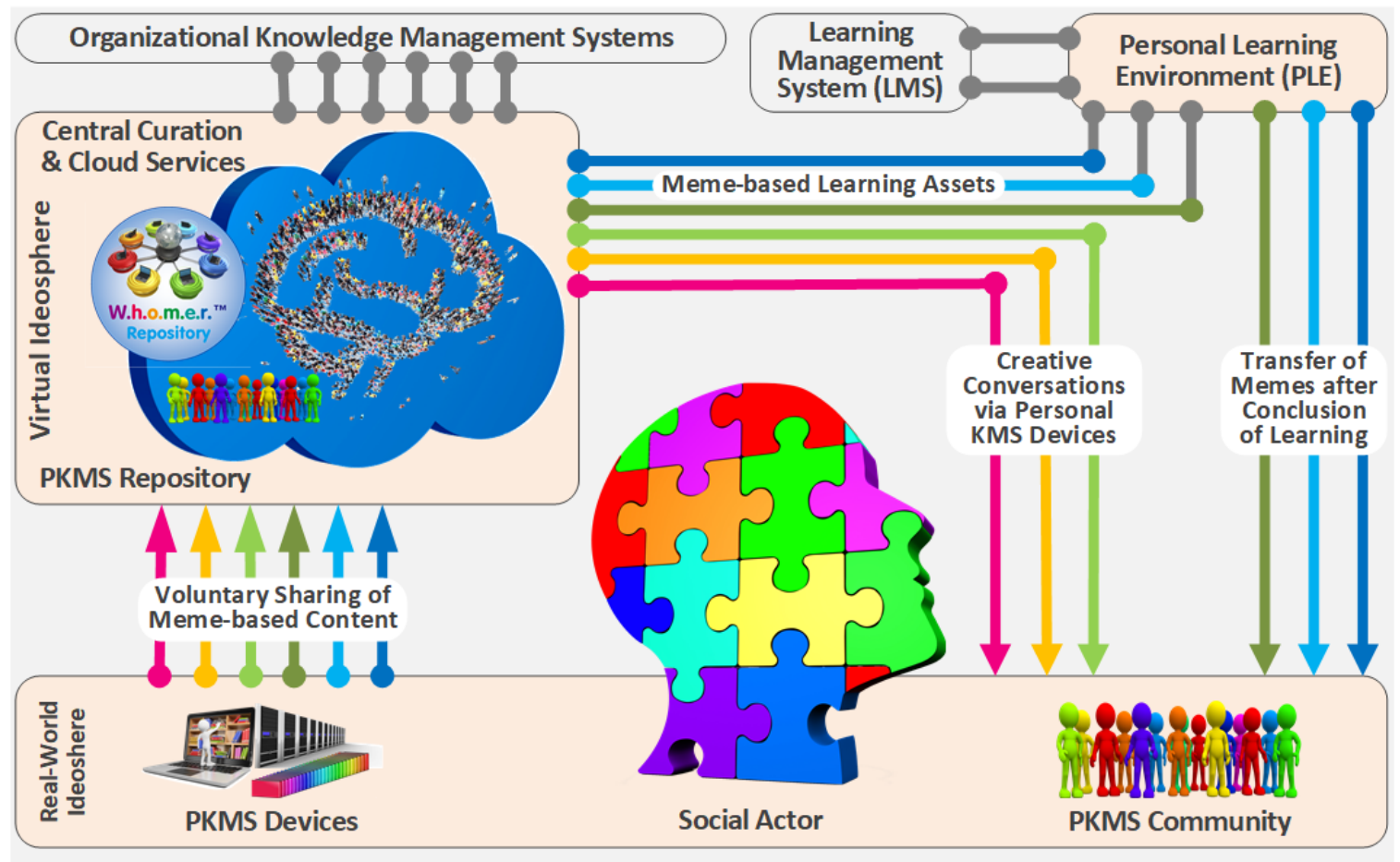

Figure 4. PKMS as a Digital Platform Ecosystem (DPE). 


\section{THE INFORMATION SPACE AND THE TECHNOLOGY ECOSYSTEM}

Information spaces represent natural and artificial areas of containment of information (tacit and/or explicit) from many different sources or environments allowing individual or collective users to utilize and add to them (Sedig et al., 2017).

The technology ecosystem as part of Popper's world:1 represents the physical objects of the external environment with their relationships and effects. Contributing to the DCAT scenario are the world:1's rising populations and higher innovation rates. As a result, not only the number of entities to deal with is growing, but their potential relationships and effects are also subjected to a combinatorial explosion and a mounting objective complexity. The accelerating change also renders physical and social technologies and their documented representations more rapidly obsolete than ever before (Schmitt, 2016a).

Individuals (hosts) as members of institutions and society (embodying the tacit uncodified knowledge of the collective human mind set) must possess the potential capacity to elaborate on knowledge and to perform those cognitive tasks that we refer to as 'understanding'. Other physical objects and artefacts (vectors) encapsulate knowledge (e.g. plants, machines, or buildings) or are utilized as containers of encoded content (e.g. books, posters, or digital files). A knowledge worker interacts with the information spaces accessible to him/her through field research (via observations and/or interviews) or desk research (via re-engineering, analysis, or reading) by collecting, analyzing, and synthesizing many diverse types of data or knowledge which may be captured explicitly at different levels of abstraction, structure, and elaboration in physical containers or digital repositories.

For further information: The PKM4A Framework (Schmitt, 2018a, Figure 2, p. 4) combines twelve currently applied renowned knowledge creation models complementing each other in a three-dimensional information space (based on Boisot, 2004) presented as a dynamic 'public-transport-like' 3D-map. The topography of this meta-perspective "emphasizes how the models represent the external environment in which the PKM devices are expected to operate in and which of the workflows suggested are suitable for supporting the internal PKMS processes" as a visual guide for knowledge workers and KM Education (Schmitt, 2018a, p. 1).

\section{THE COMPUTING SPACE AND THE IDEOSPHERE ECOSYSTEM}

The computing space processes content from the information space to fit the intended purposes. "However, data and information will remain latent within the computing space unless made access through representations encoded in the representation space" (Sedig et al., 2017).

Figure 4 provides a bird's-eye-view of the technological infrastructure (computing space) available to a social actor with the decentralized PKM devices (right) and the PKMS user community (left) depicted at the bottom, the cloud-based World Heritage of Memes Repository (WHOMER) where content is voluntarily shared and centrally curated (to reduce information entropy and assure associative integrity) on the middle-left, and the Personal Learning Environments (PLE) with their e-learning functionalities on the top-right. Interactions with external Organizational Knowledge Management Systems (OKMS) and Learning Management Systems (LMS) refer to the broader technological ecosystems alluded to.

The PKMS-DPE blueprint follows Levy's (2011) envisaged decentralized Knowledge Management Revolution that gives more power and autonomy to individuals and self-organized groups by facilitating the emergence of distributed processes of collective intelligence, which in turn feed them via creative conversations. Levy deems this sustainable growth of autonomous Personal KM Capacities to be the most important function of future education.

Contributing to the DCAT scenario is that current tools and technologies are lacking, unfortunately, support for vital PKM provisions and affordances, for personal learning environments (PLE), as well as for the mobility and portability of personal knowledge and skills (Schmitt, 2017a, pp. 72, 75) with the consequence of hampering self-development and self-actualizing capabilities as well as personal autonomy and sovereignty - as required in the DCAT-scenario. 
The progress of civilization is, nevertheless, based on changes by humans in pursuit of affordances (Schmitt, 2017a). Profound innovations are, hence, based on new ideas and affordances resulting in dominant designs (of products, processes, relations, or cultures). They forever alter existing systems and "radically restructure the relationship among manufacturers, distributors, consumers and any others in the supply chain" (Garon, 2012, pp. 442-446). The short histories of the 'world wide web' and 'cloud' can, hence, be perceived as a continuing fierce struggle for dominant designs (and business models) with quite a number of temporary winners unable to sustain their leading edges.

For future further information: A PKM4I Framework-in-progress appraises the PKMS's envisaged impact in the market place and DCAT scenario positively against the concepts and criteria of generalpurpose, disruptive, radical, and emergent innovations and also aligns the potentially transformative and game-changing but synergetic affordances to a 'Desirable Sustainability Vision' concept (Wiek \& Iwaniec, 2014) to be shared with stakeholders as a prerequisite for creating the respective future PKMS reality.

\section{THE REPRESENTATION SPACE AND THE EXTELLIGENCE ECOSYSTEM}

Data and knowledge in (artificial) information spaces are stored (extelligence) in a variety of ways from simple, atomic, and single layered to complex and multilayered and, hence, are inaccessible to users without the mediation of the other spaces in the framework (Sedig et al., 2017).

Contributing to the DCAT scenario is that buman evolution has not only thrived on communication technology, but also on an insatiable urge to use it for the purposes intended (Hughes, 2011), transforming the familiar problem of information scarcity into a never before experienced ever-increasing information abundance. These trends deplete the very attention our cognitive capabilities are able to master (Simon, 1971), especially since any part of any digital content can now be disseminated and modified unlimited times resulting in rising stakes of information entropy (replications, fragmentations, inconsistencies, untraceabilities, corruptions, decay, obsolescence, and falsifications) (Schmitt, 2016a) resulting in the increasing ruggedness of any fitness-landscape and the more complex wicked problem spaces alluded to.

It is the crucial role of the representation space to process content from the information space through the computing space and encode it into forms that are sensible (e.g. text, chart, image, video, sound) (Sedig et al., 2017) and afford transparency and productive utilization to users. Current digital formats are predominantly based on a digital emulation of printed media. They oversimplistically model digital documents as monolithic blocks of linear content and adopt the limitations of paper documents by unnecessarily replicating content via copy and paste operations (Signer, 2010) with the detrimental effects alluded to. This document-centric 'book-age' paradigm also compels us to experience our nonlinear holistic world via linear disciplinary-divided fragments (Schmitt, 2018a, p. 9).

The PKMS's shedding of current document-centric storage practices in favor of digital re-use, cumulative synthesis, associative indexing and integrity allows for 'Traceability'. It forms the back-bone of modern manufacturing by tracing the history, application or location of an entity by creating as-built genealogies across diverse value chains and sources. The multi-disciplinary PKM publications (memetically represented) already populate (and add to the test data set of) the PKMS knowledge base (WHOMER). This digital content is planned to be re-employed and re-aligned to an established Learning Management System (LMS) which shares the same philosophy of cutting information redundancy and entropy by repurposing knowledge and learning objects across different contexts (Schmitt \& Saade, 2017).

For further information: The PKMS relies on the digital re-use of captured unique basic information units (ideas or memes) to be used like building blocks. The PKM4M (PKM for Meme Modification) framework (Schmitt, 2017b, Figure 1, p. 3) demonstrate that "any of these memes and their metadata can be simply re-posited in their original 'as-is' states or changed by modifying their attributes (differentiated by codification, container, or context) to evolve - with repeated utilization over time - into an increasingly complex construct" (Schmitt, 2017b, p. 3) to form Knowledge Assets or to create 
Learning Assets to populate e-learning structures supported by the LMS. Memes, knowledge and learning assets are accessible by the PKMS community and may be integrated into members' PKMS devices.

\section{THE INTERACTION SPACE AND THE INSTITUTIONS ECOSYSTEM}

All actions and the range of subsequent reactions and feedbacks afforded in the interaction space (and facilitated by the representation or computing spaces) allow users to dynamically explore, transform, and better use the information within the information space. They may enable rich, multifaceted, continuous discourses resulting in new insights and perspectives but also present the risk to confuse, distract, or overwhelm thinking (Sedig et al., 2017).

A key to personal career potential is, thus, absorptive capacity ( $A C)$, one's ability to recognize, assimilate, and apply new valuable information. Organizational leadership is eager to convert these potential $A C s$ (as dispersed individually over their knowledge workers) into their firm's realized $A C$, because their success rests on converting tacit into explicit actionable knowledge, on aggregating individual into organizational performance, and on balancing between the exploiting of current capabilities versus exploring new ventures, all by dealing with unfamiliarity and perceived difficulties in the VUCA and DCAT environments mentioned.

Empirical findings imply leverage by strengthening employees' intrinsic (over and above extrinsic) motivation as well as their perceived organizational commitment to learning (Tian \& Soo, 2018). Since the strongest creativity-innovation-association have been found to reside at individual rather than team levels, firms are advised to "identify, nurture, and effectively deploy ambidextrous" knowledge workers to better support both, the exploitation and exploration of ideas (Sarooghi, Libaers, \& Burkemper, 2015).

While the PKMS concept sheds centralized institutional approaches in favor of personal affordances, it does not seek to impede but rather fruitfully co-evolve with Organizational KM. Based on mutually beneficial interests of PKM-OKM users in collectively harvesting prior accumulated knowledge subsets and on a common ground of methodologies, PKMSs are expected "to strengthen the absorptive capacity, ambidexterity, and resulting dynamic capability of organizations considerably, not at the expense of disinterested employees, but as a means to motivate them by serving their [very] selfinterests" (Schmitt, 2015c; 2016c).

For future further information: Strengthening individual sovereignty and personal utility is, hence, not a contradiction, but a viable strategy for improving institutional competitiveness, as argued in context of traditional top-down KM system generations and their lack of success and acceptance (Schmitt, 2015c), ambidextrous organizations, and Earl's seven KM schools (Schmitt, 2016c). The latter also forms the basis for the PKM4O Framework (Schmitt, 2018d, Figure 1, p. 4) and the role of PKMSs for entrepreneurship and SMEs.

\section{THE MENTAL SPACE AND KNOWLEDGE WORKER / SOCIETY ECOSYSTEM}

The mental space refers to the users' minds and the internal cognitive processes necessary to benefit from opportunities by successfully utilizing, complementing, and sharing content (Sedig et al., 2017). But, the associated "skills and knowledge, along with attitudes toward IT, [need to] coalesce in the context of reflective self-awareness and purposeful intent to allow one to achieve generativity - the ability to generate new skills and knowledge that form the basis for innovation and creativity" (Pérez \& Murray, 2010, p. 132).

For further information: The PKM4E Framework (Schmitt, 2018b, Figure 3, p.133) synthesizes and visualizes concepts related to ignorance and entropy, learning and innovation, chance discovery and abduction by integrating them with cycles of learning and fallacies/wastes. It supports Usher's (2013) 
concept of Cumulative Synthesis which convincingly couples the activities of researchers and entrepreneurs and assists them in advancing their capability endowments in light of increasing path entropy.

Contributing to the DCAT scenario are, nonetheless, the unequal effects of diffusing digital technologies which produce detrimental opportunity divides across societies worldwide and increase social complexities. While digital divides describe "the uneven distribution of ICT across society, distinguishing between 'digerati' and 'have-nots", innovation divides label gaps "in technology creation [between innovators and non-innovators] and thus in ownership of the related intellectual property" (Drori, 2010). It is, hence, crucial that all countries "take advantage of science, technology and innovation as fundamental elements for their development strategies, poverty reduction and the construction of a Knowledge Society" (OAS, 2005).

For further information: The PKM4D Framework (Schmitt, 2016b, Figure 2, p.10) allows for tackling these opportunity divides by prioritizing affordances, knowledge workers need to be provided with in a DCAT scenario. It "raises awareness, helps to self-reflect, to channel one's ambitions, and to set one's personal targets" by differentiating socially relevant desires into twelve criteria closely aligned to Maslow's Extended Hierarchy of Needs. It provides an integrative heuristic motivational scaffold matching the ambitions of the users the PKMS serves and adds transparency to assessing sustainable interventions in the individual, organizational, and societal capacity development contexts of opportunity divides and knowledge societies.

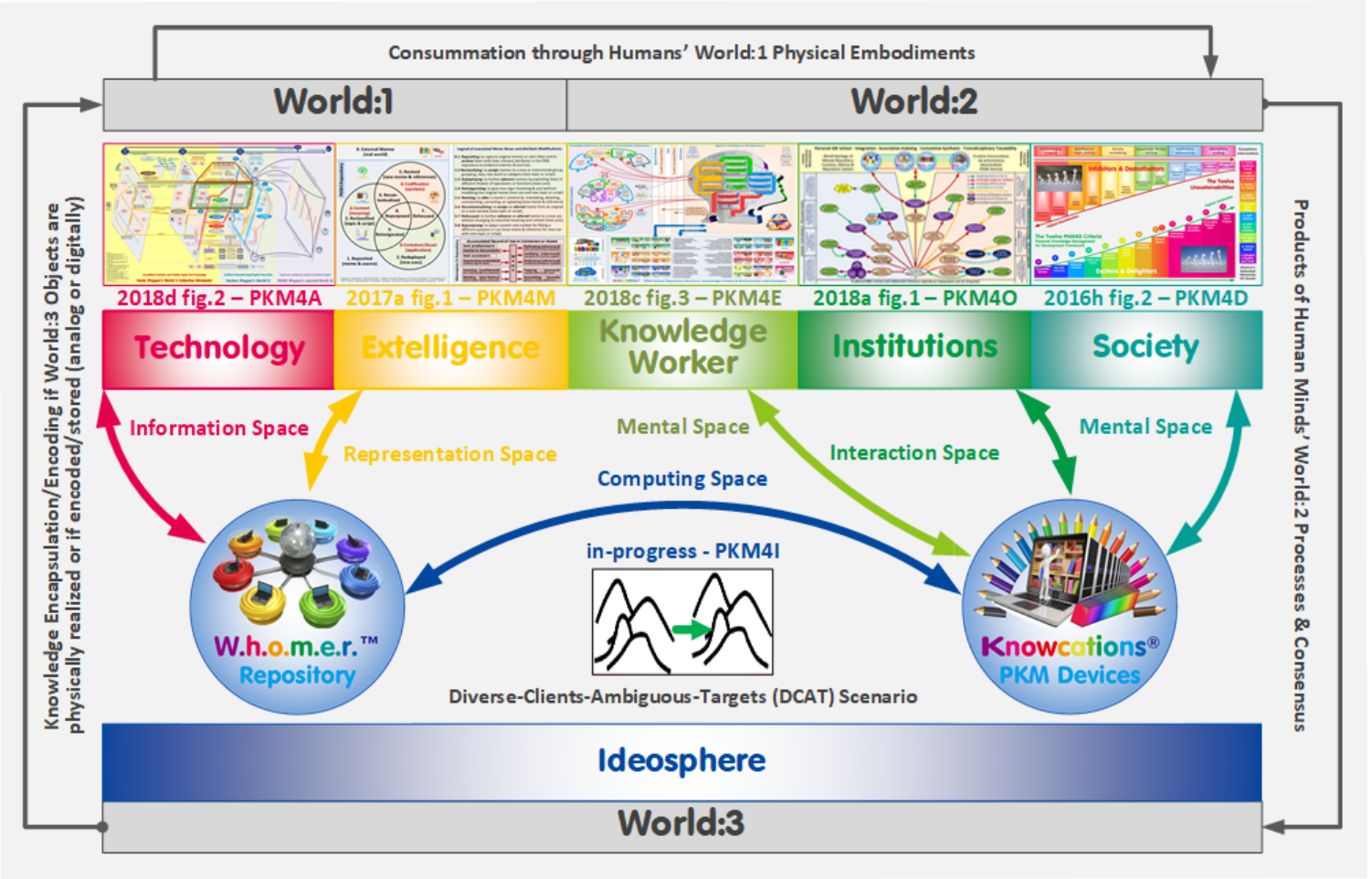

Figure 5. PKMS-DPE's digital ecosystems in their envisaged conceptual sustainable state

\section{SUMMARY}

Figure 5's visual summary provides the conceptual counterpart of the technological overview (Figure 4) and a sustainable vision to the unsustainable status quo (Figure 3). As Figure 4 illustrates, the PKMS's 'World Heritage of Memes Repository (WHOMER) repository forms the heart of the proposed PKMS-DPE as a representation of knowledge through which other worlds, ecosystems, spaces, and devices can interact. The PKMS platform itself provides the necessary tools for growing, curating, and querying the repository. 
The five thumbnails added in Figure 5 refer to their larger visualized PKM4x (for Action, Meme Modification, Empowerment, Organization, and Development) frameworks cited for further information (Schmitt, 2016b, 2017b, 2018a, 2018c, 2018d) in support of the PKMS's educational dimensions and for assisting prospective PKMS community members to understand the PKMS concepts and benefits.

The insignificance of Popper's world:3 for current KM practices has been symbolized by its isolated position in Figure 3, whereas Figures 4 and 5 depict it as the central enabler within the PKMS-DPE. The reason is that the PKMS focuses our precious attention by removing redundant information and embedding digital references, benefiting creative authorship and novel learning and collaboration experiences. Since anything (in a standardized memetic format) is expressible, combinable and curatable, linked distinctive memes of diverse disciplines are able to materialize as a single unified negentropic transdisciplinary knowledge repository (WHOMER) which - assisted by the network effects of increasing adoption rates - is expected to rapidly grow its novel as well as its historic content (promoting the fitness characteristic of antifragility, a quality not ensured in today's fragmented world:1 extelligence, as argued in a prior article based on the scheme of small-and-big-T-theories (Schmitt, 2016a, pp. 357-360; O’Raghallaigh, Sammon, \& Murphy, 2011).

\section{RELATING PKMS TO THE FUM, IS AND DSR FRAMEWORKS}

\section{PKM ACCORDING TO THE FITNESS-UTILITY MODEL (FUM)}

We now consider how the various elements of the proposed PKMS seem positioned to adapt and evolve using the constructs of the earlier described fitness-utility design science research model.

The more technically oriented utility and usefulness has been checked against the criteria of generalpurpose, disruptive, radical, and emergent innovations and is founded on the PKMS's envisaged dominant design based on a holistic bottom-up approach indicating adaptability to diverse contexts and on anticipated productivity improvements and quasi-irreversibility providing leverage for the PKMS choice.

The evolutionary fitness-characteristics described are clustered into resonance fitness (relating to novelty, interestingness, elegance) and process fitness (relating to decomposability, malleability, openness). The latter process fitness characteristics together with preventing an instantiated artefact from becoming 'too useful' also represent evolutionary fitness (reproducing or adapting to change to evolve over successive generations). The embeddedness-in-design-systems-fitness need to be differentiated; while instantiated artefacts may effect actual immediate and wider socio-technical-informational environments concerned with artefact change, (meta-)artefacts would integrate other complementary meta-artefacts with tools, methods, or processes to allow for modifications (Drechsler, 2017, pp. 4, 8; Gill \& Hevner, 2013).

- Resonance fitness mainly relies on the PKMS's informational generativity:

Elegance: Ecosystems and workflows are closely aligned to organizational KM philosophies as, for example, the SECI-Ba-model (Nonaka, Toyama, \& Konno, 2000). Adaptive features minimize distraction and reduce cognitive load by extracting "the patterns of the world - its redundancy - so that far less information needs to be read, written, or stored" (Simon, 1971). Novelty: The PKMS adheres to six vital PKM provisions currently not catered for: (1) digital personal and personalized knowledge stays always in the possession and at the personal disposal of its owner or eligible co-worker; (2) based on standardized, consistent, transparent, flexible, secure, and non-redundant formats as well as (3) independent of changes in one's social, educational, professional, or technological environment; (4) a 'World Heritage of Memes Repository (WHOMER)' reduces information redundancies and unlocks collaboration capabilities between the decentralized autonomous PKMS capacities; (5) to be mutually beneficial by facilitating consolidated team or institutional actions; and (6) the PKM approach is also based on sound educational interventions (Schmitt, 2014, 2015d). The novelty 
of the PKMS has been ascertained via the innovation criteria mentioned and resulted in the PKM for Impact and Innovation (PKM4I) framework. The entropy reduction via WHOMER's curation services also allows for establishing a tangible Popperian third world. Interestingness: The PKMS's communicative and educational aspects (use of analogies, metaphors, visuals, maps, frameworks, concepts, and schemes) establishes an enabling evocative environment to be further promoted by its LMS-related e-learning facilities. People currently negatively affected by opportunity divides are empowered through their PKMS devices to become beneficiaries of and/or contributors to the world record (WHOMER repository).

- Process fitness:

Decomposability allows for mutation, modification, and recombination, a feature which the PKMS affords through its utilization of memes for creating more complex knowledge and learning assets.

Malleability can be characterized as the degree to which users of artefacts are enabled to customize or adapt it to their own needs; needs that have frequently not been anticipated in its original design. The PKMS supports the notions of cumulative synthesis and effectuation (adopted from entrepreneurship research to pursue "possibilities that can be achieved with extant means and resources" by focusing on "opportunities, contingencies, flexibility, and emergence") in mind (Drechsler \& Hevner, 2015, pp. 1, 4). The resulting personal knowledge base is biographically self-determined and allows for partial voluntary sharing and advancement via accessing WHOMER.

Openness can be characterized as the degree to which an artifact is transparent and accessible to the user community that it serves. It is achieved by the PKMS's technical transferability due to the interrelatedness of its components and content, by the ease of mastery due to learning effects, by the social generativity due to high stakeholders' allegiance, and by the intended positioning as a social machine together with its educational dimension.

Antifragility fully applies as already pointed out in respect to the single unified negentropic transdisciplinary WHOMER repository.

- Evolutionary fitness is assured by following principles where the association of thoughts and memes (instead of search-and-index dominated document-centricity) leads to intellectual progressions or processes, and by effecting associative indexing and integrity to facilitate more rapid iterative improvement, wider and faster sharing and diffusion of ideas, and advanced citation, reputation and impact metrics (Nielsen, 2011).

It is further promoted by complementary innovations in downstream sectors due to the social generativity of expanding collaborative PKMS spaces (among a growing PKMS community and in co-evolution with organizational KMSs) as well as spawning innovations due to the effects and potentials (evocative informational generativity) of PKMS's meme-based (entropy and cognitive-load reducing) processes and more productive environments. Open-ended (further and novel) currently unimagined uses and applications are likely to be triggered by the abstract Popperian world: 3 being transformed into a tangible accessible interrogatable repository.

- Embeddedness fitness as an instantiated artefact includes its capacity to generate and modify different artefacts (memes, knowledge and learning assets). It is currently being evaluated from a systemic-roots-perspective of sustaining or disruptive innovations, differentiable according to products (focus on utility gaps and chances), processes (focus on effectiveness), relations (focus on social relevance), or cultural shifts (focus on adapting and innovating) (Garon, 2012). The results show that all four focal points of disruptive innovation apply.

- Embeddedness fitness as a meta-artefact entails the envisaged co-evolutions with organizational KMS and Learning Management Systems (LMS). In the wider context, the PKMS has been evaluated from a General-Purpose-Technology (GPT) perspective (Schmitt, 2015a) demonstrating that all twelve 'general-purpose' premises and promises (including innovation spawning) are well-supported. The findings are currently actualized by furnishing the potentially disruptive PKMS innovation with a Desirable Sustainability Vision. 


\section{PKMS AND THE GENERIC INFORMING SCIENCE FRAMEWORK}

As previously described, the IS-Framework (Figure 1) visualizes "the informer, information transmission and receiving media, and receiver of information" and "explicitly acknowledges that they exist within complex environments [...] influenced by environmental context" (Cohen, 2009, p.8). In the PKMS context, its trifold application imposes its informer-transformation-client sequences clockwise on the PKMS workflow resulting in a generic meta-system at a high level of abstraction (Figure 6).

Following the IS-Meta-Approach to Modelling, the three IS-Frameworks (further qualified by the five framework spaces) "portray the environment promoting informing, whereas the related subordinate models and methodologies [exemplified by bullet points] embody central design elements of the blueprints on which the PKM concept and system are based" (Schmitt, 2015b, p. 151):

- The real world's explicit/tacit knowledge exists in hosts and vectors and can be interpreted as memes and meme pools in an Ideosphere (I) which - in their role as informers (Ia) interact (I:P) with individual human clients or knowledge workers $(\mathrm{Pa})$. These individuals $(\mathrm{Pa})$ are simultaneously represented in the Ideosphere (I) as PKMS clients by their personally hosted meme pool (Ib).

- As PKMS users/informers (Pb), the knowledge workers communicate via the human-computerinterface (P:R) with the PKMS system/client to store/represent captured memes as information and knowledge in the PKMS repositories (R).

- In following user interventions, the PKMS-as-informer $(\mathrm{T})$ utilizes its repositories $(\mathrm{R})$ by either giving feedback (T:I) to its own user, publishing to vectors, or by sharing with or giving access to other hosts. This process serves the diverse meme pools/clients in the ideosphere by promoting or further spreading existing memes and/or by introducing new memes (Ib). These activities are illustrated in Figure 6.

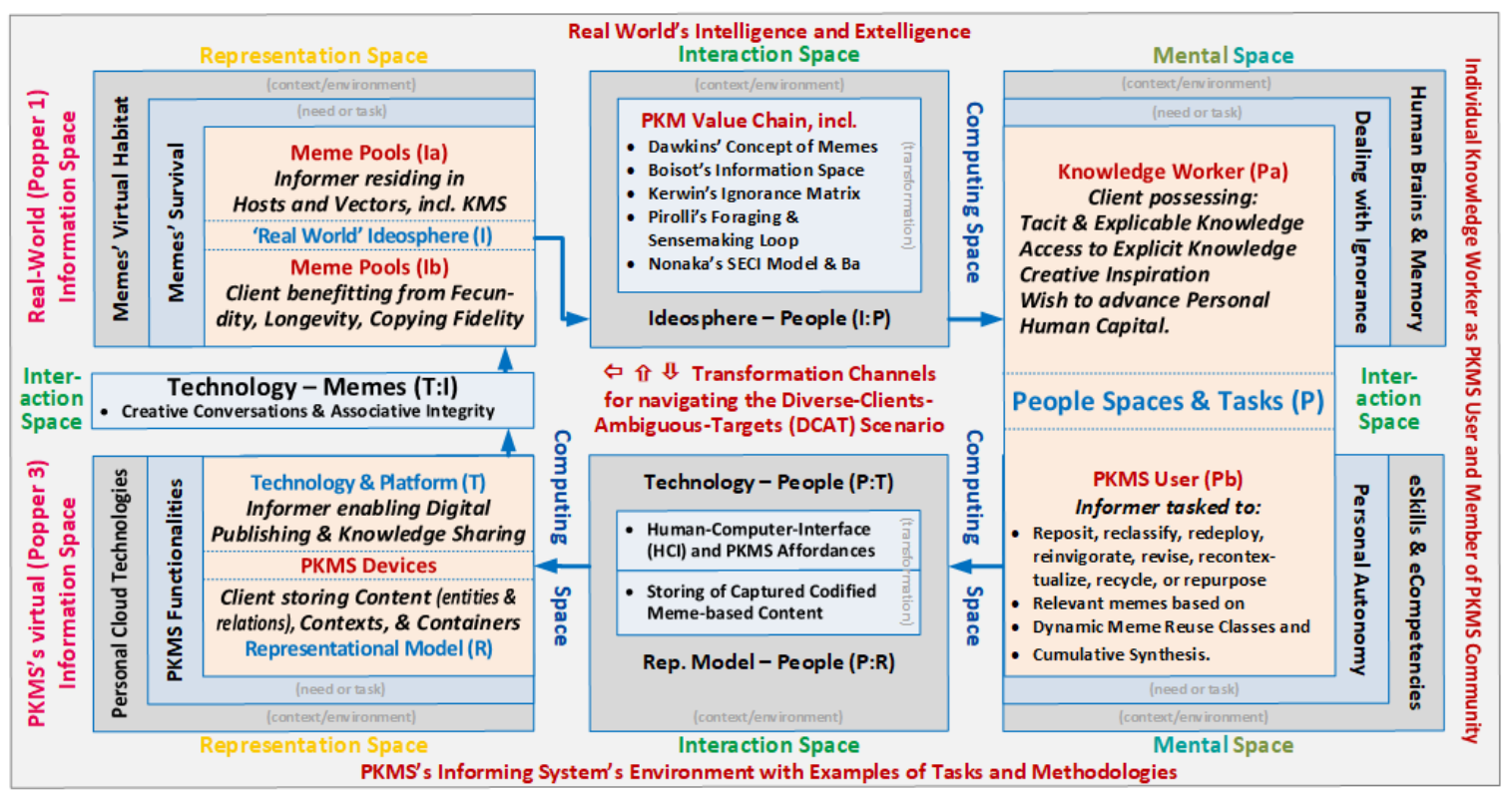

Figure 6. PKMS's triple application of generic IS-framework (Schmitt, 2015b revised)

As a Social Macbine, the PKMS-DPE differs from "conventional IT systems dedicated to data- and computation-intensive tasks [by] offering some combination of well-known participatory features, in which user-generated content and the underlying social network evolve dynamically and hand-inhand" (Shadbolt et al., 2013, pp. 1, 4, 5). Accordingly, it is able to adequately respond to groundgaining calls for decentralizing KM operations, raising user autonomy, addressing information overload, and 
encouraging innovation (Bedford, 2013; Cabitza, Simone, \& Cornetta, 2015; Lebow, 2018; Levy, 2011; Papapanagiotou et al., 2018; Lebow, 2018).

\section{PKMS AND DESIGN SCIENCE RESEARCH}

Motivated by validation needs, the designing and prototyping process of the PKMS has already demonstrated its adherence to a range of IS and DSR principles in prior publications: IS Systems Thinking Techniques (e.g. IS-Framework, Diamond Model, IS-Meta Approach, and Design Task Complexity Model) were employed to align, introduce, and visualize the more specific Knowledge Management (KM) models and methodologies central to the PKMS concept (Schmitt, 2015b). The Design Thinking approaches adopted and the DSR Guidelines followed to structure the underlying rational and creative processes of the PKMS Development were outlined (Schmitt, 2016a). Based on former affordance-related publications (focusing on communication, community-building, collaboration, and social knowledge sharing), the common and differing narratives in relation to PKM were investigated in order to suggest further PKM Capabilities and Affordances in need to be conferred (Schmitt, 2017a).

Subsequently, the visualized PKM4x Frameworks referred to have been devised for further support of the PKMS's Theory Effectiveness, a DSR notion calling for theories to be incrementally and iteratively designed to be purposeful - both in terms of their utility (largely a matter of content) but also in their communication (largely a question of presentation) to an audience and stakeholders (O’Raghallaigh et al., 2011). In addition, the SVIDT Methodology has been applied (Schmitt, 2018c).

The DSR contribution of this article is the expansion of these PKM-related publications and frameworks in light of the latest Informing and Design Science Research concerning sustainable fitness in dynamic contexts and environments. We further seek to add a 'vice versa' application-oriented as well as concepts-synthesizing PKMS-perspective to the IS and DRS research agenda and consider the dynamic fitness characteristics alluded to in the realm of recent generativity conceptualizations.

\section{CONCLUSIONS}

As presented, the PKMS is based on an IS artefact design aiming for sustained life-cycle utility and impact (adherence to the fitness-utility DSR model) and exemplifies a digital platform ecosystems (DPE). It provides participating uncoordinated third-party actors (diverse PKMS community members with ambiguous targets as portrayed in the DCAT scenario) with a self-contained digital system (socio-technical-informational artefact or social 'informing' machine) that facilitates information storage, processing, and transformation (capturing of memes into knowledge repositories) for creating new outputs (originating of memes), structures (knowledge and learning assets), and behaviors (learning, authorship, and creative conversations/collaborations) endogenously (within its relevant technological and conceptual digital ecosystems) without individual client customization by the system's originator (but based on range of conferred affordances and curation services). Its benefits and impact stem from the PKMS's capacity to generate and modify different artefacts (creation of knowledge assets by digitally embedding and reusing parts of digital documents (memes) via structural references (Signer, 2010)) with their need to be instantiated and introduced to specific local application contexts (via workflows supporting knowledge socialization, externalization, combining, and internalization), which also qualifies it as a meta-artefact.

As a sustainable KM intervention, a PKMS accommodates diverse set of initial and target states (Figure

2) and allows PKMS community member to pinpoint and pursue quite different informing paths and outcomes for attaining fitness. It rules out traditional generalized one-size-fits-all approaches in favor of facilitating individual client-centric path discovery and path steering. From Gill's and Mullarkey's (2017) informer's perspective, such approaches will increasingly need to be devised and employed in the context of a research philosophy that encourages crossing disciplinary boundaries.

Traditionally, the technical IT component of an information system artefact is a means to an end. The PKM concept and system, accordingly, affords decentralized networked devices linked to the WHOMER repository (the means) to confront opportunity divides (the end) independent of space 
(e.g., developed/developing countries), time (e.g., study or career phase), discipline (e.g., natural or social science), or role (e.g., student, professional, or leader). Accordingly, it is also predestined to serve educators, mentors, consultants, and leaders to support fellow individuals in their selfdevelopment and/or guide appropriate interventions for transforming individual into organizational or societal performances.

\section{REFERENCES}

Bedford, D. A. D. (2013). Knowledge management education and training in academic institutions in 2012. Journal of Information \& Knowledge Management, 12(4). https://doi.org/10.1142/S0219649213500299

Boisot, M. (2004). Exploring the information space: A strategic perspective on information systems. Working Paper Series WP04-003. University of Pennsylvania.

Cabitza, F., Simone, C., \& Cornetta, D. (2015). Sensitizing concepts for the next community-oriented technologies: shifting focus from social networking to convivial artefacts. The Journal of Community Informatics, 11(2). Retrieved from http://ci-journal.net/index.php/ciej/article/view/1155/1151

Cohen, E. B. (2009). A philosophy of informing science. Informing Science, 12(1), 15. https://doi.org/10.28945/425

Drechsler, A. (2015). Designing to inform: toward conceptualizing practitioner audiences for socio-technical artefacts in design science research in the information systems discipline. Informing Science, 18, 31-45. https://doi.org/10.28945/2288

Drechsler, A. (2017). Designing for change and transformation: Exploring the role of IS artefact generativity. Australasian Conference on Information Systems, Hobart, Australia.

Drechsler, A. \& Hevner, A. (2015). Effectuation and its implications for socio-technical design science research in information systems. In B. Donnellan, R. Gleasure, M. Helfert, J. Kenneally, M. Rothenberger, M. Chiarini Tremblay, D. Vandermeer, \& R. Winter (Eds.), At the vanguard of design science: First impressions and early findings from ongoing research. Research-in-Progress Papers and Poster Presentations from the $10^{\text {th }}$ International Conference, Dublin, Ireland, pp. 77-84.

Drori, G. S. (2010). Globalization and technology divides: Bifurcation of policy between the 'digital divide' and the 'innovation divide'. Sociological Inquiry, 80(1), 63-91.https://doi.org/10.1111/j.1475-682X.2009.00316.x

Eck, A., \& Uebernickel, F. (2016). Untangling generativity: Two perspectives on unanticipated change produced by diverse actors. Proceedings of the Twenty-Fourth European Conference on Information Systems (ECIS), Istanbul, Turkey, 35.

Garon, J. M. (2012). Mortgaging the meme: financing and managing disruptive innovation. North-Western Journal of Technology and Intellectual Property, 10(7), 441-483.

Gill, T. G. (1995). High-tech hidebound: Case studies of information technologies that inhibited organizational learning. Accounting, Management and Information Technologies, 5(1), 41-60. https://doi.org/10.1016/0959$\underline{8022(95) 90013-6}$

Gill, T. G. (2016). Informing Science, Volume I: Systems and concepts. Sanata Rosa, CA: Informing Science Press.

Gill, T. G., \& Hevner, A. R. (2013). A fitness-utility model for design science research. ACM Transactions on Management Information Systems (TMIS), 4(2), 5. https://doi.org/10.1145/2499962.2499963

Gill, T. G., \& Mullarkey, M. (2017). Fitness, extrinsic complexity and informing science. Informing Science, 20. https://doi.org/10.28945/3668

Gill, T. G., \& Murphy, W. (2011, July). Task complexity and design science. Proceedings of the 9 th International Conference on Education and Information Systems, Technologies and Applications (EISTA), Orlando, FL.

Hevner, A., March, S., Park, J., \& Ram, S. (2004). Design science research in information systems. MIS Quarterly, 28(1), 75-105. https://doi.org/10.2307/25148625

Hughes, J. (2011). On the origin of tepees. New York, NY: Free Press. 
Synthesizing Design and Informing Science Rationales

Lebow, D. G. (2018). A social machine for transdisciplinary research. Informing Science, 21, 201-217. https://doi.org/10.28945/4025

Levy, P. (2011). The semantic sphere 1. Computation, Cognition and Information Economy. Hoboken, NY: Wiley.

Murphy, W. F., Murphy, S., Buettner Jr, R. R., \& Gill, T. G. (2015). Case study of a complex informing system: Joint interagency field experimentation (JIFX). Informing Science, 18. https://doi.org/10.28945/2289

Nielsen, M. (2011). Reinventing discovery - The new era of networked science. Princeton, NJ: Princeton University Press.

Nonaka, I., Toyama, R., \& Konno, N. (2000). SECI, ba and leadership: A unified model of dynamic knowledge creation. Long Range Planning, 33, 5-34. https://doi.org/10.1016/S0024-6301(99)00115-6

O’Raghallaigh, P., Sammon, D., \& Murphy, C. (2011). The design of effective theory. Systems, Signs \& Actions, 5(1), 117-132.

OAS. (2005). Science, technology, engineering and innovation for development: A vision for the Americas in the twenty-first century. Organization of American States.

Papapanagiotou, P., Davoust, A., Murray-Rust, D., Manataki, A., Van Kleek, M., Shadbolt, N., \& Robertson, D. (2018, July). Social machines for all. Proceedings of the 17th International Conference on Autonomous Agents and MultiAgent Systems, 1208-1212.

Pérez, J., \& Murray, M. C. (2010). Generativity: The new frontier for information and communication technology literacy. Interdisciplinary Journal of Information, Knowledge, and Management, 5, 127-137. https://doi.org/10.28945/1134

Popper, K. (1972). Objective knowledge - An evolutionary approach. Oxford, UK: Oxford University Press.

Popper, K. (1978, April). Three worlds. The Tanner lecture on human values. Paper presented at the University of Michigan, MI.

Rylander, A. (2009). Design thinking as knowledge work: Epistemological foundations and practical implications. Design Management Journal, 4(1), 7-19. https://doi.org/10.1111/j.1942-5074.2009.00003.x

Sarooghi, H., Libaers, D., \& Burkemper, A. (2015). Examining the relationship between creativity and innovation: A meta-analysis of organizational, cultural, and environmental factors. Journal of Business Venturing, 30(5), 714-731. https://doi.org/10.1016/j.jbusvent.2014.12.003

Schmitt, U. (2014, June). Overcoming the seven barriers to innovating personal knowledge management systems. International Forum on Knowledge Asset Dynamics (IFKAD), Matera, Italy. Retrieved from https://doi.org/10.13140/2.1.3789.2800

Schmitt, U. (2015a, July). Knowledge management systems as an interdisciplinary communication and personalized general-purpose technology. Special Issue of the Journal of Systemics, Cybernetics and Informatics 2015: Invited Papers of the Plenary Keynote Speakers at the IMS 2015 Conferences $\left(9^{\text {th }}\right.$ International Multi-Conference on Society, Cybernetics and Informatics), Orlando, Florida, US A, 1690-4524. Retrieved from http://www.researchgate.net/publication/278784977

Schmitt, U. (2015b). Putting personal knowledge management under the macroscope of informing science. Informing Science, 18, 145-175. https://doi.org/10.28945/2161

Schmitt, U. (2015c). Quo Vadis, knowledge management: A regeneration or a revolution in the making? Journal of Information \& Knowledge Management, 14(4). https://doi.org/10.1142/S0219649215500306

Schmitt, U. (2015d). Towards a 'world heritage of memes repository' for tracing ideas, tailoring knowledge assets and tackling opportunity divides: Supporting a novel personal knowledge management concept. The International Journal of Technology, Knowledge \& Society: Annual Review, 10, 25-44. http://www.researchgate.net/publication/277469690

A Schmitt, U. (2016a). Design science research for personal knowledge management system development revisited. Informing Science, 19, 345-379. https://doi.org/10.28945/3566

Schmitt, U. (2016b). Personal knowledge management for development (PKM4D) framework and its application for people empowerment. Elsevier Procedia Computer Science, 99C, 64-78.

https://doi.org/10.1016/i.procs.2016.09.101 
Schmitt, U. (2016c). Tools for exploration and exploitation capability: Towards a co-evolution of organizational and personal knowledge management systems. The International Journal of Knowledge, Culture, and Change Management: Annual Review, 15, 23-47. Retrieved from http://www.researchgate.net/publication/282852429

Schmitt, U. (2017a). Devising enabling spaces and affordances for personal knowledge management system design. Informing Science, 20, 63-82. https://doi.org/10.28945/3743

Schmitt, U. (2017b, April). The logic of use and functioning of personal KM-supported experience management. $7^{\text {th }}$ German Workshop on Experience Management (GWEM) within the $9^{\text {th }}$ Conference on Professional Knowledge Management (ProWM), Karlsrube, Germany. Retrieved from http://www.researchgate.net/publication/313999664

Schmitt, U. (2018a, November). Effectuating tacit and explicit knowledge via personal knowledge management frameworks and devices. Proceedings of the 15th International Conference on Intellectual Capital, Knowledge Management \& Organisational Learning (ICICKM), Cape Town, South Africa.

Schmitt, U. (2018b). From ignorance map to informing PKM4E framework: Personal knowledge management for empowerment. Issues in Informing Science and Information Technology, 15, 125-144. https://doi.org/10.28945/4017

Schmitt, U. (2018c). Rationalizing a personalized conceptualization for the digital transition and sustainability of knowledge management using the SVIDT method. Sustainability, 10(3), 839. https://doi.org/10.3390/su10030839

Schmitt, U. (2018d). Supporting the sustainable growth of SMEs with content- and collaboration-based personal knowledge management systems. The Journal of Entrepreneurship and Innovation in Emerging Economies (JEIEE), 4(1), 1-21. https://doi.org/10.1177/2393957517739773

Schmitt, U., \& Saade, R. G. (2017, June). Taking on opportunity divides via smart educational and personal knowledge management technologies. Proceedings of the 12th International Conference on e-Learning (ICEL), Orlando, Florida, 188-196. Retrieved from http://www.researchgate.net/publication/313842489

Scholz, R. W. (2017). Digital threat and vulnerability management: The SVIDT method. Sustainability, 9 , 554. https://doi.org/10.3390/su9040554

Sedig, K., Naimi, A., \& Haggerty, N. (2017). Aligning information technologies with evidence-based health-care activities: A design and evaluation framework. Human Technology, 13.

Shadbolt, N. R., Smith, D. A., Simperl, E., Van Kleek, M., Yang, Y., \& Hall, W. (2013). Towards a classification framework for social machines. Proceedings of the $22^{\text {nd }}$ International Conference on World Wide Web (pp. 905-912). New York, NY: ACM. https://doi.org/10.1145/2487788.2488078

Shannon, C. E. \& Weaver, W. (1949). The mathematical theory of communications. Urbana, IL: University of Illinois Press.

Signer, B. (2010). What is wrong with digital documents? A conceptual model for structural cross-media content composition and reuse. Conceptual Modeling-ER 2010 (pp. 391-404). Berlin: Springer. https://doi.org/10.1007/978-3-642-16373-9 28

Simon, H. A. (1971). Designing organizations for an information-rich world. In M. Greenberger (Ed.), Computers, communication, and the public interest. Baltimore: Johns Hopkins Press.

Tian, A. W., \& Soo, C. (2018). Enriching individual absorptive capacity. Personnel Review, 47(5), 1116-1132. https://doi.org/10.1108/PR-04-2017-0110

Usher, A. P. (2013). A history of mechanical inventions: Revised edition. New York: Dover Publications.

Wiek, A., \& Iwaniec, D. (2014). Quality criteria for visions and visioning in sustainability science. Sustainability Science, 9(4), 497-512. https://doi.org/10.1007/s11625-013-0208-6 


\section{BIOGRAPHIES}

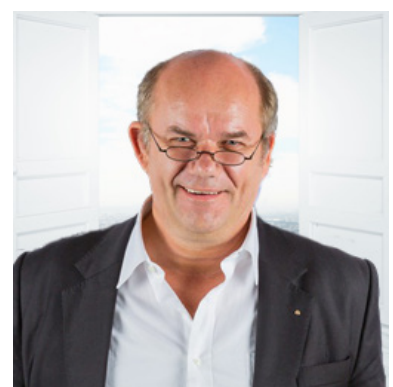

Ulrich Schmitt's professional background includes IT and management consultant positions (London, Basle), professor and vice president at two independent German universities, Vice Rector (Polytechnic of Namibia) and Dean of the Graduate School (University of Botswana). He studied Management and Industrial Engineering (TU Berlin, Cranfield University), completed his PhD (Basle University) and a Science \& Research Management Program (Speyer University). Focussing on Knowledge Management, he is currently Professor at the University of Stellenbosch Business School.

http://www.researchgate.net/profile/Ulrich Schmitt2

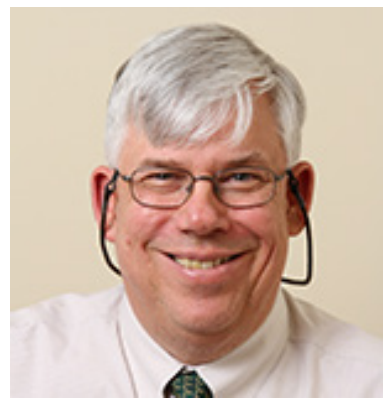

Grandon Gill is a professor in the Information Systems and Decision Sciences Department of the University of South Florida. He is also the Academic Director of the Doctor of Business Administration program at the Muma College of Business. He is Editor-in-Chief of the Journal of IT Education: Discussion Cases, also serving as a Governor and Fellow of the Informing Science Institute. In 2014, he was the inaugural recipient of the Zbigniew Gackowski Award for contributions to informing science research. 